\title{
Phosphatidylinositol 3-Kinase Couples Localised Calcium Influx to Activation of Akt in Central Nerve Terminals
}

\author{
Jessica C. Nicholson-Fish ${ }^{1}$ Michael A. Cousin ${ }^{1} \cdot$ Karen J. Smillie $^{1}$
}

Received: 9 April 2015/Revised: 23 June 2015/Accepted: 10 July 2015/Published online: 22 July 2015

(C) The Author(s) 2015. This article is published with open access at Springerlink.com

\begin{abstract}
The efficient retrieval of synaptic vesicle membrane and cargo in central nerve terminals is dependent on the efficient recruitment of a series of endocytosis modes by different patterns of neuronal activity. During intense neuronal activity the dominant endocytosis mode is activity-dependent endocytosis (ADBE). Triggering of ADBE is linked to calcineurin-mediated dynamin I dephosphorylation since the same stimulation intensities trigger both. Dynamin I dephosphorylation is maximised by a simultaneous inhibition of its kinase glycogen synthase kinase 3 (GSK3) by the protein kinase Akt, however it is unknown how increased neuronal activity is transduced into Akt activation. To address this question we determined how the activity-dependent increases in intracellular free calcium $\left(\left[\mathrm{Ca}^{2+}\right]_{\mathrm{i}}\right)$ control activation of Akt. This was achieved using either trains of high frequency action potentials to evoke localised $\left[\mathrm{Ca}^{2+}\right]_{\mathrm{i}}$ increases at active zones, or a calcium ionophore to raise $\left[\mathrm{Ca}^{2+}\right]_{\mathrm{i}}$ uniformly across the nerve terminal. Through the use of either non-specific calcium channel antagonists or intracellular calcium chelators we found that Akt phosphorylation (and subsequent GSK3 phosphorylation) was dependent on localised $\left[\mathrm{Ca}^{2+}\right]_{\mathrm{i}}$ increases at the active zone. In an attempt to determine mechanism, we antagonised either phosphatidylinositol 3-kinase (PI3K) or calmodulin. Activitydependent phosphorylation of both Akt and GSK3 was arrested on inhibition of PI3K, but not calmodulin. Thus
\end{abstract}

Special Issue: In honor of Dr. Philip Beart.

\section{Karen J. Smillie}

K.Smillie@ed.ac.uk

1 Centre for Integrative Physiology, University of Edinburgh, Hugh Robson Building, George Square, Edinburgh EH8 9XD, Scotland, UK localised calcium influx in central nerve terminals activates PI3K via an unknown calcium sensor to trigger the activity-dependent phosphorylation of Akt and GSK3.

Keywords Endocytosis - Vesicle · Presynapse · Calcium $\cdot$ Exocytosis $\cdot$ Akt $\cdot$ GSK3

\section{Introduction}

Central nerve terminals rely on the efficient recycling of a limited supply of synaptic vesicles (SVs) in order to maintain neurotransmission. This is achieved via recruitment of a number of SV endocytosis modes [1, 2]. Clathrin-mediated endocytosis is dominant during low frequency stimulation and generates SVs directly from the plasma membrane whereas ultrafast endocytosis can be triggered by single action potentials at physiological temperatures and generates SVs via an endosomal intermediate [3-5]. During higher stimulation intensities an additional endocytosis mode is triggered to increase retrieval capacity called activity-dependent bulk endocytosis (ADBE). ADBE generates large endosomes direct from the plasma membrane. These bulk endosomes then donate SVs back to the recycling pool via clathrin-dependent mechanisms [2, $6]$.

Triggering of ADBE is dependent on the dephosphorylation of the large GTPase dynamin I at two serine residues (Ser774 and Ser778) [7]. This event is mediated by the calcium-dependent protein phosphatase calcineurin and only occurs during intense activity [7]. ADBE is maintained across multiple trains of stimuli via the rephosphorylation of dynamin I by cyclin-dependent kinase 5 on Ser778 and then subsequently by glycogen synthase kinase 3 (GSK3) on Ser774 [8]. 
GSK3 has a high basal activity which is regulated via its phosphorylation status [9]. Phosphorylation of Ser21/9 of GSK3 $\beta / \alpha$ by upstream cascades inhibits this protein kinase activity. We have shown that GSK3 is phosphorylated in central nerve terminals only during high levels of neuronal activity, coincident with dynamin I dephosphorylation [10]. We also identified that the activity-dependent GSK3 kinase was Akt (also known as protein kinase B). This activity-dependent inhibitory signalling cascade ensures that Ser774 on dynamin I is maximally dephosphorylated during periods of intense activity [10]. Importantly, either expression of constitutively active Akt or addition of signalling molecules such as brain-derived neurotrophic factor (BDNF, which activates Akt) reduces ADBE in cultured neurons [10, 11] suggesting that this activity-dependent signalling cascade is essential for efficient presynaptic function during intense neuronal activity.

It is currently unclear how action potential stimulation is transduced into activation of Akt. To address this we monitored the phosphorylation status of both Akt and GSK3 after elevating intracellular free calcium $\left(\left[\mathrm{Ca}^{2+}\right]_{\mathrm{i}}\right)$ via either action potentials or a calcium ionophore. We found that localised $\left[\mathrm{Ca}^{2+}\right]_{\mathrm{i}}$ increases via voltage gated calcium channels were essential for Akt activation. This activation was dependent on phosphatidylinositol 3-kinase (PI3K) but not calmodulin activity. This reveals a key role for PI3K in the activity-dependent control of GSK3 activity, but leaves the identity of the calcium sensor still undetermined.

\section{Materials and Methods}

\section{Materials}

Foetal bovine serum was from Biosera. Penicillin/streptomycin and Minimum Essential Medium were from Invitrogen. The primary antibodies phospho-Akt Ser473 and GSK3 $\alpha / \beta$ Ser21/9 were from Cell Signalling. Bovine serum albumin was from Roche. BAPTA-AM, CNQX and AP-5 were from Tocris. EGTA-AM was from Cambridge Bioscience and ionomycin from Merck Chemicals. Secondary antibodies, $\beta$-Actin antibody, LY294002, wortmannin and all other chemicals were bought from Sigma.

\section{Cerebellar Granule Neuron Cultures}

Cerebellar granule neuron (CGN) cultures were prepared from the cerebella from P7 Sprague-Dawley rat pups of either sex [12]. Cultures were used between 8 and 14 days in vitro (DIV).

\section{CGN Lysis Experiments}

Cerebellar granule neurons (CGNs) were repolarised in incubation medium $(170 \mathrm{mM} \mathrm{NaCl}, 3.5 \mathrm{mM} \mathrm{KCl}, 400 \mu \mathrm{M}$ $\mathrm{KH}_{2} \mathrm{PO}_{4}, 20 \mathrm{mM}$ TES [ $N$-tris(hydroxy-methyl)-methyl-2aminoethane-sulfonic acid], $5 \mathrm{mM} \mathrm{NaHCO} 3,5 \mathrm{mM}$ glucose, $1.2 \mathrm{mM} \mathrm{Na}_{2} \mathrm{SO}_{4}, 1.2 \mathrm{mM} \mathrm{MgCl}_{2}, 1.3 \mathrm{mM} \mathrm{CaCl}_{2}$ at $\mathrm{pH}$ 7.4) for $10 \mathrm{~min}$. This medium was then replaced by media supplemented with (2R)-amino-5-phosphonovaleric acid (AP-5, $50 \mu \mathrm{M}), \quad 6$-cyano-7-nitroquinoxaline-2,3-dione (CNQX, $10 \mu \mathrm{M}$ ) and various antagonists as described in the respective figure legends. For electrical field stimulation experiments coverslips were placed in a Warner imaging chamber (RC-21 BRFS) and either challenged with a train of 800 action potentials delivered at $80 \mathrm{~Hz}$ or no stimulus (basal). In experiments using ionomycin, cells were treated in an identical manner, with the exception that the challenge with $2.5 \mu \mathrm{M}$ ionomycin or a vehicle control (DMSO) was for $1 \mathrm{~min}$. In all experiments antagonists were present during stimulation with the exception of those using either BAPTAAM or EGTA-AM. Low calcium incubation medium had the following alterations, $\mathrm{CaCl}_{2}$ was reduced to $100 \mu \mathrm{M}, \mathrm{MgCl}_{2}$ was increased to $10 \mathrm{mM}$ and EGTA was added at $50 \mu \mathrm{M}$. After stimulation with either action potentials or ionomycin, CGNs were immediately lysed in $25 \mu \mathrm{l}$ of SDS sample buffer (67 mM Tris, $9.3 \%$ glycerol, 2 mM EGTA, 67 mM SDS, bromophenol blue, $12 \% \beta$-mercaptoethanol) and boiled at $95{ }^{\circ} \mathrm{C}$ for at least $5 \mathrm{~min}$.

\section{Western Blotting}

Cerebellar granule neuron (CGN) lysates were subjected to Western blotting as described before [12]. Primary antibodies were all used at 1:1000, apart from HRP-coupled Anti- $\beta$-Actin (1:50,000). Secondary antibodies were used at 1:5000 except for Anti- $\beta$-Actin where no secondary was required. The intensity of the detected chemiluminescence signal was determined using Image J (NIH). Raw densitometry values were normalised firstly to the highest value within an individual blot and then to individual corresponding loading controls ( $\beta$-Actin, which was also normalised to the highest value). All Western blot data is displayed after normalisation to the basal signal from each blot. All data was analysed using GraphPad Prism and with students $\mathrm{t}$ tests performed between basal and stimulated states as well as between stimulated states across conditions. 


\section{Results}

\section{An Intracellular Free Calcium Increase is Essential for Phosphorylation of Akt/GSK3}

The strict activity-dependence of both Akt and GSK3 phosphorylation [10] suggests an essential requirement for increased $\left[\mathrm{Ca}^{2+}\right]_{\mathrm{i}}$. To assess the importance of increased $\left[\mathrm{Ca}^{2+}\right]_{\mathrm{i}}$ on both Akt and GSK3 phosphorylation, the calcium ionophore ionomycin was employed to uniformly increase $\left[\mathrm{Ca}^{2+}\right]_{\mathrm{i}}$ independent of depolarisation. Phosphorylation of both Akt and GSK3 was observed when CGNs were challenged with ionomycin in the presence of extracellular calcium (Fig. 1). However no evoked increase was observed when this experiment was repeated in low calcium buffer (Fig. 1), indicating that increased $\left[\mathrm{Ca}^{2+}\right]_{i}$ in the absence of membrane depolarization is sufficient to cause activation of this signalling cascade.

Increased presynaptic $\left[\mathrm{Ca}^{2+}\right]_{i}$ during action potential stimulation is usually a result of activation of voltage-gated calcium channels. To confirm that calcium entry via these channels was responsible for Akt and GSK3 phosphorylation during action potential stimulation, we employed the non-selective calcium channel inhibitor flunarizine [13]. CGN cultures were stimulated with a train of 800 action potentials $(80 \mathrm{~Hz})$ a stimulus protocol that ensures maximal Akt and GSK3 phosphorylation [10]. As expected, a robust activity-dependent phosphorylation of both Akt (Fig. 2b) and GSK3 (Fig. 2c) was observed in the absence of flunarizine. In contrast, incubation with flunarizine $(10 \mu \mathrm{M})$ resulted in a complete block of activity-dependent Akt and GSK3 phosphorylation (Fig. 2a-c). To ensure that this inhibition was due to blockade of calcium channels, these experiments were repeated with ionomycin stimulation, which increases $\left[\mathrm{Ca}^{2+}\right]_{i}$ independently of calcium channel activation. Flunarizine had no effect on ionomycin-evoked Akt/GSK3 phosphorylation (Fig. 2d-f), illustrating that its inhibition of activity-dependent phosphorylation was not due to off-target effects on $\left[\mathrm{Ca}^{2+}\right]_{i}$ levels. Thus influx of extracellular calcium via voltagegated calcium channels is essential for activation of the Akt/GSK3 phosphorylation cascade during intense neuronal activity.

\section{A Localised $\left[\mathrm{Ca}^{2+}\right]_{\mathrm{i}}$ Increase is Essential for Akt/ GSK3 Phosphorylation}

In central nerve terminals voltage-gated calcium channels are clustered at the active zone. During action potential stimulation the opening of these channels generates a localised microdomain of high $\left[\mathrm{Ca}^{2+}\right]_{\mathrm{i}}$ which is required for neurotransmitter release [14]. We next determined
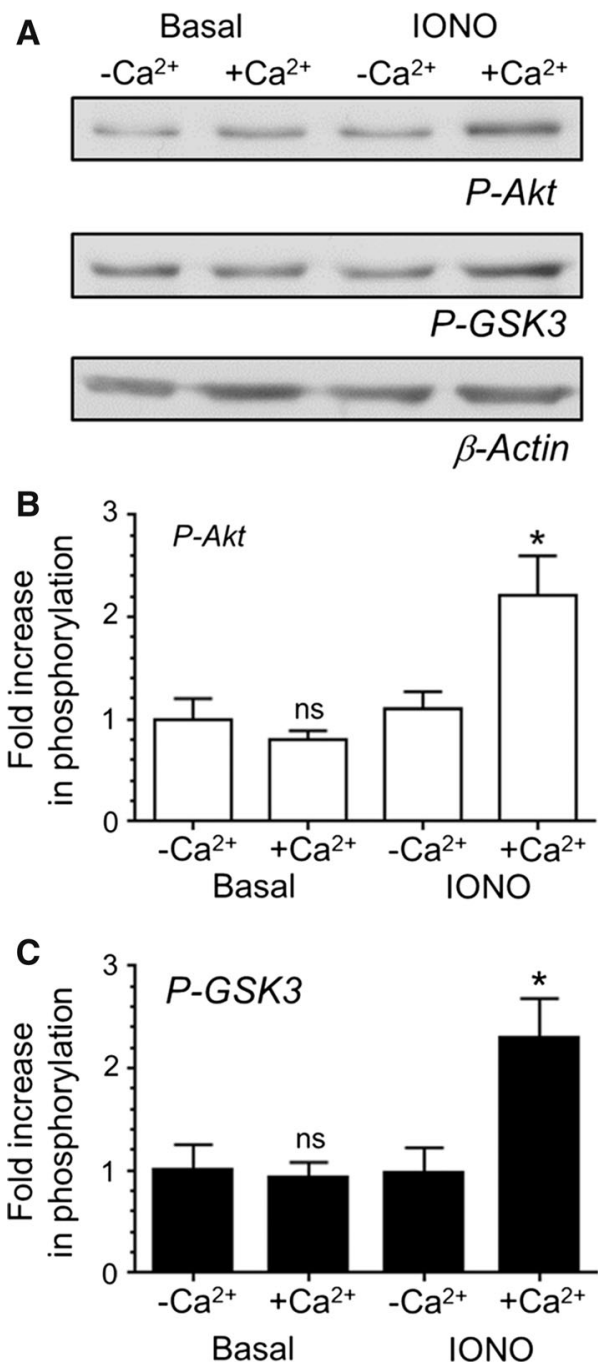

Fig. $1\left[\mathrm{Ca}^{2+}\right]_{\mathrm{i}}$ increases are essential for Akt/GSK3 phosphorylation. CGNs were removed from culture medium and repolarised in incubation medium for $10 \mathrm{~min}$. Cultures were then either rested (Basal) or stimulated with ionomycin (IONO, $5 \mu \mathrm{M}$ ) for $1 \mathrm{~min}$ in incubation buffer containing either $1.3 \mathrm{mM}\left(+\mathrm{Ca}^{2+}\right)$ or low $\left(-\mathrm{Ca}^{2+}\right)$ calcium. a Representative blots are displayed showing either Akt Ser473 phosphorylation $(P-A k t)$, GSK3 $\alpha / \beta$ Ser21/9 phosphorylation $(P$-GSK3) or $\beta$-Actin levels $(\beta$-Actin). $\mathbf{b}$, c The fold increase in phosphorylation of either Akt Ser473 (b, open bars) or GSK3 $\alpha / \beta$ Ser21/9 (c, closed bars) is displayed after correction for protein levels using $\beta$-Actin and normalisation to the low calcium control. All error bars represent \pm SEM; $\mathrm{n}=5$ for P-Akt and $\mathrm{n}=4$ for P-GSK3 (students $t$ test, $n s$ non-significant, $* p<0.05,-\mathrm{Ca}^{2+}$ to $+\mathrm{Ca}^{2+}$ per condition)

whether this localised microdomain is also required for Akt and GSK3 phosphorylation during intense neuronal activity by challenging CGNs with a train of 800 action potentials after prior treatment with the calcium chelators BAPTAAM and EGTA-AM (both $100 \mu \mathrm{M}$ ). Both chelators have the same affinity for calcium but a different on-rate for binding, meaning BAPTA-AM effectively buffers $\left[\mathrm{Ca}^{2+}\right]_{\mathrm{i}}$ increases at the active zone, whereas EGTA-AM does not 
A
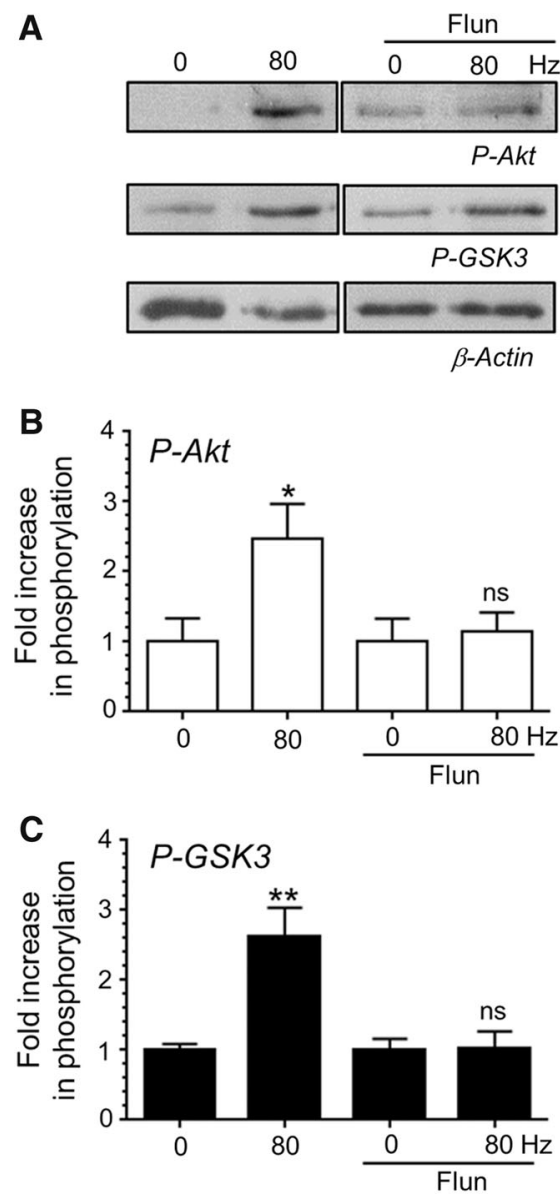

Fig. $2 \mathrm{Ca}^{2+}$ influx via voltage-gated calcium channels is essential for Akt/GSK3 phosphorylation. CGNs were removed from culture medium and repolarised in incubation medium for $10 \mathrm{~min}$. Cultures were then incubated with or without incubation medium supplemented with $10 \mu \mathrm{M}$ flunarizine (Flun) for $10 \mathrm{~min}$. After this point CGNs were left to rest or challenged with either 800 action potentials $(80 \mathrm{~Hz})$ or ionomycin (IONO, $2.5 \mu \mathrm{M}$ for $1 \mathrm{~min}$ ). a, d Representative blots are displayed showing either Akt Ser473 phosphorylation $(P$ $A k t)$, GSK3 $\alpha / \beta$ Ser21/9 phosphorylation $(P-G S K 3)$ or $\beta$-Actin levels $(\beta$-Actin) after either action potential (a) or ionomycin (d) stimulation.

[14]. Both chelators efficiently buffer activity-dependent $\left[\mathrm{Ca}^{2+}\right]_{\mathrm{i}}$ increases outside the active zone. The action potential-evoked increase in both Akt and GSK3 phosphorylation was abolished in CGNs treated with BAPTA$\mathrm{AM}$, confirming the requirement for increased $\left[\mathrm{Ca}^{2+}\right]_{\mathrm{i}}$ (Fig. 3a-c). Interestingly, CGNs treated with EGTA-AM displayed a robust activity-dependent phosphorylation of both Akt and GSK3 (Fig. 3a-c). This suggests that the localised increase in $\left[\mathrm{Ca}^{2+}\right]_{i}$ at the active zone during action potential stimulation is essential for the phosphorylation of Akt and GSK3. Importantly, both BAPTA-AM and EGTA-AM arrested phosphorylation of Akt and GSK3 evoked by ionomycin (Fig. 3d-f). This was expected, since ionomycin increases $\left[\mathrm{Ca}^{2+}\right]_{\mathrm{i}}$ globally across the nerve terminal. Thus during intense neuronal activity, a localised
D
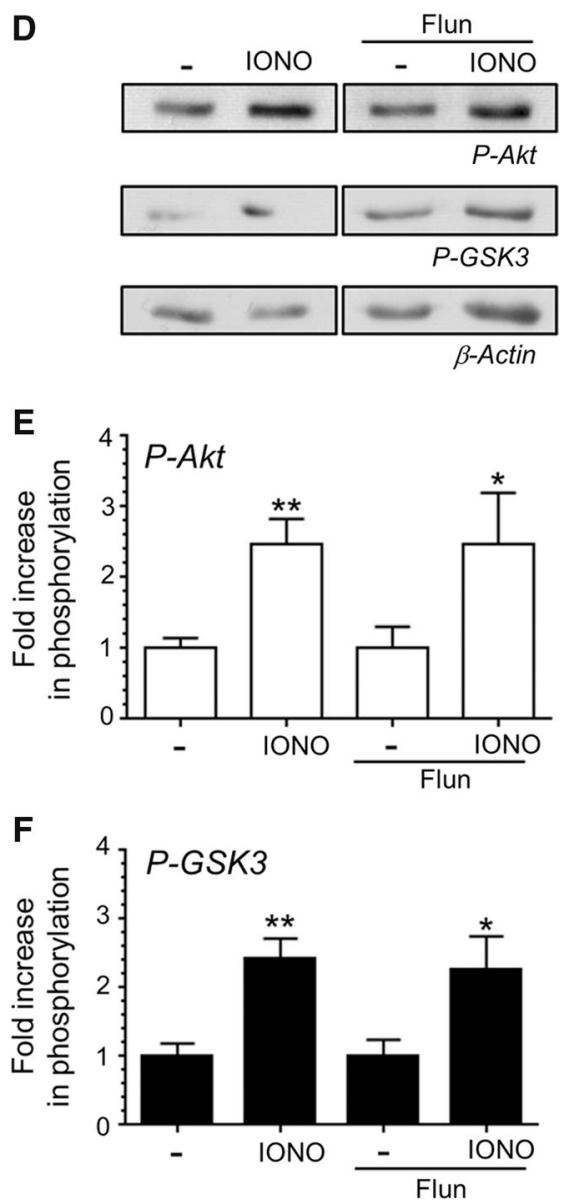

b, $\mathbf{e}$ The fold increase in phosphorylation of Akt Ser473 (open bars) in response to either action potentials (b) or ionomycin (e) is displayed. $\mathbf{c}, \mathbf{f}$ The fold increase in phosphorylation of GSK3 $\alpha / \beta$ Ser21/9 (closed bars) in response to either action potentials (c) or ionomycin (f) is displayed. In all cases phosphorylation levels were corrected for protein levels using $\beta$-Actin and normalisation to the basal controls. All error bars represent $\pm \mathrm{SEM} ; \mathrm{n}=5$ for both P-Akt and P-GSK 3 with $80 \mathrm{~Hz}, \mathrm{n}=6$ for P-Akt IONO and $\mathrm{n}=7$ for P-GSK3 IONO (students $t$ test, $n s$ non-significant, $* p<0.05$; $* * p<0.01$ either basal to $80 \mathrm{~Hz}$ or basal to ionomycin per condition)

increase in $\left[\mathrm{Ca}^{2+}\right]_{\mathrm{i}}$ at the active zone is essential for triggering both Akt and GSK3 phosphorylation.

\section{PI3K Activity is Required for Activity-Dependent Akt and GSK3 Phosphorylation}

To understand how activity-dependent calcium influx is coupled to downstream Akt and GSK3 phosphorylation we examined the role of PI3K. PI3K activity plays a key role in phosphorylation of Akt and subsequently GSK3 after addition of the signalling molecule BDNF to CGNs [10], however it is not known whether action potentials activate the same signalling pathway. To determine the role for PI3K in activity-dependent Akt and GSK3 phosphorylation, the PI3K inhibitors LY294002 $(10 \mu \mathrm{M})$ and 
A

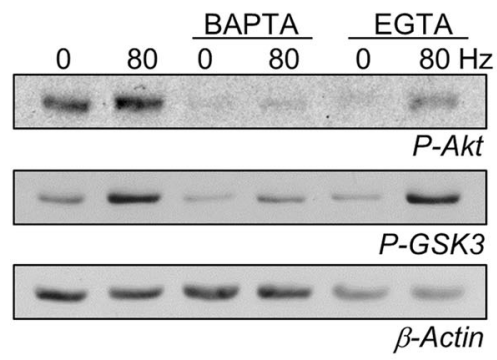

B
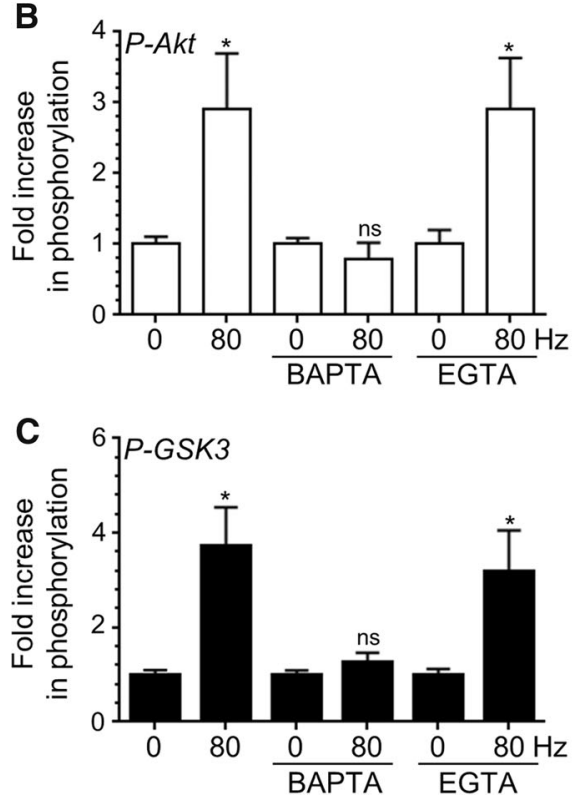

Fig. 3 Localised $\mathrm{Ca}^{2+}$ influx is essential for Akt/GSK3 phosphorylation. CGNs were removed from culture medium and repolarised in incubation medium for $10 \mathrm{~min}$. Cultures were then incubated with or without incubation medium supplemented with either $100 \mu \mathrm{M}$ BAPTA-AM or EGTA-AM for $30 \mathrm{~min}$. After this point CGNs were left to rest or challenged with either 800 action potentials $(80 \mathrm{~Hz})$ or ionomycin (IONO, $2.5 \mu \mathrm{M}$ for $1 \mathrm{~min}$ ). a, d Representative blots are displayed showing either Akt Ser473 phosphorylation $(P-A k t)$, GSK3 $\alpha / \beta$ Ser21/9 phosphorylation $(P$-GSK3) or $\beta$-Actin levels $(\beta$ Actin) after either action potential (a) or ionomycin (d) stimulation. b,

wortmannin $(200 \mathrm{nM})$ were used. Inhibition of PI3K with either LY294002 or wortmannin resulted in an arrest of activity-dependent Akt phosphorylation evoked by a train of 800 action potentials (Fig. 4). In addition LY294002 and wortmannin also significantly reduced GSK3 phosphorylation (Fig. 4). Thus intense neuronal activity results in activation of PI3K, which triggers activity-dependent Akt and GSK3 phosphorylation.

In order to transduce activity-dependent calcium influx into activation of PI3K, a calcium sensor must be present in nerve terminals, most probably at the active zone. One potential sensor is the calcium binding protein calmodulin [15]. Calmodulin can directly activate PI3K on elevation of $\left[\mathrm{Ca}^{2+}\right]_{\mathrm{i}}$ [16] and is thought to be required for
D
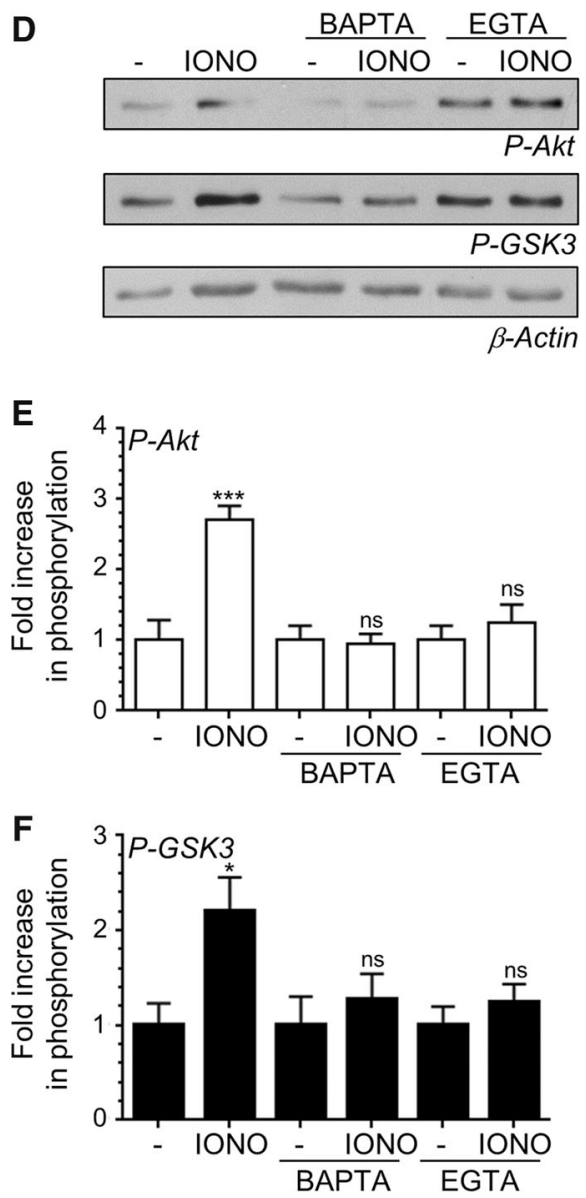

e The fold increase in phosphorylation of Akt Ser473 (open bars) in response to either action potentials (b) or ionomycin (e) is displayed. c, $\mathbf{f}$ The fold increase in phosphorylation of GSK $3 \alpha / \beta$ Ser21/9 (closed bars) in response to either action potentials (c) or ionomycin (f) is displayed. In all cases phosphorylation levels were corrected for protein levels using $\beta$-Actin and normalisation to the basal controls. All error bars represent $\pm \mathrm{SEM} ; \mathrm{n}=4$ for P-Akt $80 \mathrm{~Hz}, \mathrm{n}=5$ for P-GSK3 $80 \mathrm{~Hz}, \mathrm{n}=7$ for P-Akt IONO and $\mathrm{n}=6$ for P-GSK3 IONO (students $t$ test, $n s$ non-significant $* p<0.05 ; \quad * * p<0.01$, $* * * p<0.001$ basal to $80 \mathrm{~Hz}$ or basal to ionomycin per condition)

calcineurin activation during intense neuronal activity [17]. To determine whether calmodulin can transduce increased $\left[\mathrm{Ca}^{2+}\right]_{\mathrm{i}}$ into PI3K activation (and downstream Akt/GSK3 phosphorylation) we used the antagonist calmidazolium. Incubation with calmidazolium $(10 \mu \mathrm{M})$ during stimulation with 800 action potentials had no significant effect on the activity-dependent phosphorylation of either Akt or GSK3 (Fig. 5a-c). Interestingly when $\left[\mathrm{Ca}^{2+}\right]_{\mathrm{i}}$ was raised globally with ionomycin, calmidazolium abolished both Akt and GSK3 phosphorylation (Fig. 5d-f). Thus the activity-dependent calcium sensor for activation of the PI3K/Akt/GSK3 cascade is not calmodulin, however this cascade can be activated via calmodulin via global $\left[\mathrm{Ca}^{2+}\right]_{\mathrm{i}}$ increases. 
A

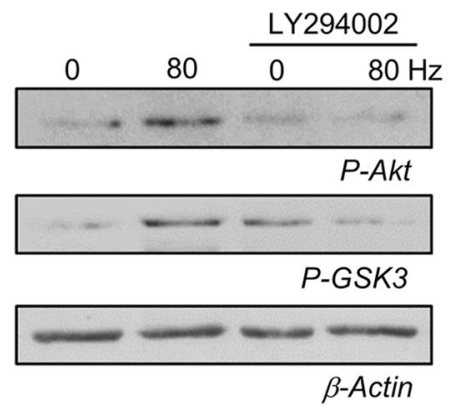

B
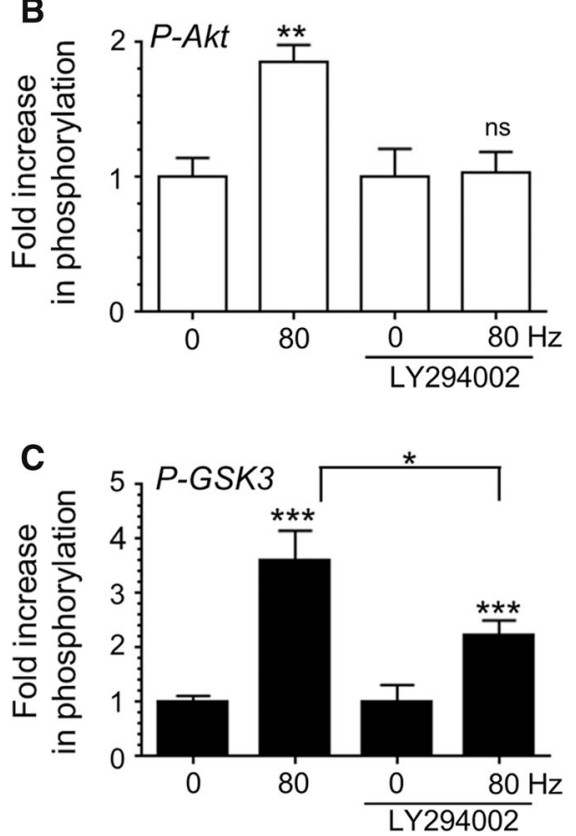

Fig. 4 PI3K activity is essential for activity-dependent Akt/GSK3 phosphorylation. CGNs were removed from culture medium and repolarised in incubation medium for $10 \mathrm{~min}$. Cultures were then incubated with or without incubation medium supplemented with either $10 \mu \mathrm{M}$ LY294002 or $200 \mathrm{nM}$ wortmannin for $10 \mathrm{~min}$. After this point CGNs were left to rest or challenged with either 800 action potentials $(80 \mathrm{~Hz})$. a, d Representative blots are displayed showing either Akt Ser473 phosphorylation $(P-A k t)$, GSK3 $\alpha / \beta$ Ser21/9 phosphorylation $(P-G S K 3)$ or $\beta$-Actin levels ( $\beta$-Actin) after action potential stimulation in the presence of either LY294002 (a) or

\section{Discussion}

The maintenance of neurotransmission during intense neuronal activity is reliant on the integration of activitydependent calcium influx, multiple signalling cascades and several SV endocytosis modes $[1,2]$. One such cascade is the activity-dependent inhibition of GSK3 via Akt, which is essential for the efficient dephosphorylation of dynamin I, a key event in the triggering of ADBE $[10,11]$. We show here that localised calcium influx via voltage-gated channels is essential for this event to occur. Furthermore we have demonstrated a key role for PI3K, but not calmodulin,
D

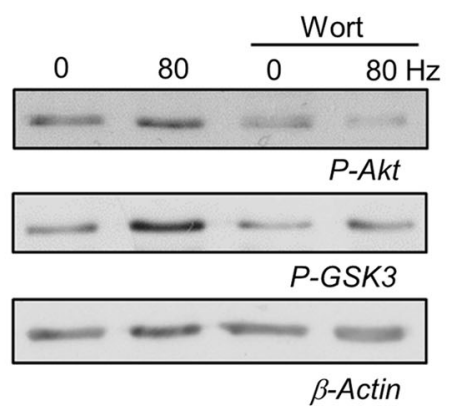

E
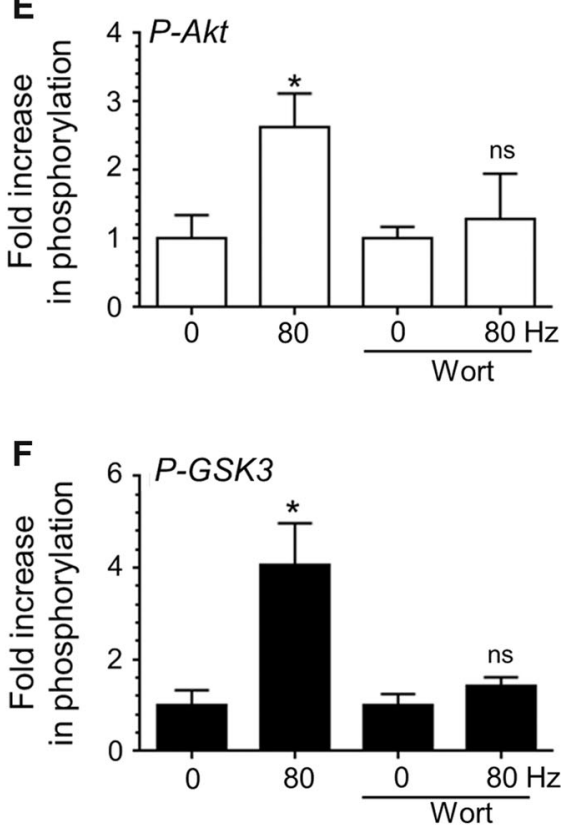

wortmannin (d). b, e The fold increase in phosphorylation of Akt Ser473 (open bars) in the presence of either LY294002 (b) or wortmannin (e). c, f The fold increase in phosphorylation of GSK3 $\alpha / \beta$ Ser21/9 (closed bars) in the presence of either LY294002 (c) or wortmannin (f). In all cases phosphorylation levels were corrected for protein levels using $\beta$-Actin and normalisation to the basal controls. All error bars represent \pm SEM; LY294002- $\mathrm{n}=6$ for P-Akt, $\mathrm{n}=16$ for P-GSK3; wortmannin- $\mathrm{n}=4$ for P-Akt, $\mathrm{n}=6$ for P-GSK3 (students $t$ test, $n s$ non-significant, $* p<0.05$; $* *<0.01$; $* * * p<0.001$ basal to $80 \mathrm{~Hz}$ per condition)

in transduction of activity-dependent calcium influx into activation of Akt.

PI3K is implicated in the regulation of secretion and membrane trafficking in a variety of systems [18-21]. One member of this family, PI3K-Class $2 \alpha$ (PI3K-C2 $\alpha$ ), regulates exocytosis either indirectly via modulation of signalling pathways [22] or directly via control of the molecular fusion machinery [23, 24]. PI3K-C2 $\alpha$ enzymatic activity is stimulated by calcium [25] and the $\mathrm{N}$-terminus contains a clathrin binding site required for recruitment of the vesicle uncoating machinery [26]. This suggests that PI3K-C2 $\alpha$ may be a good candidate involved in 
A

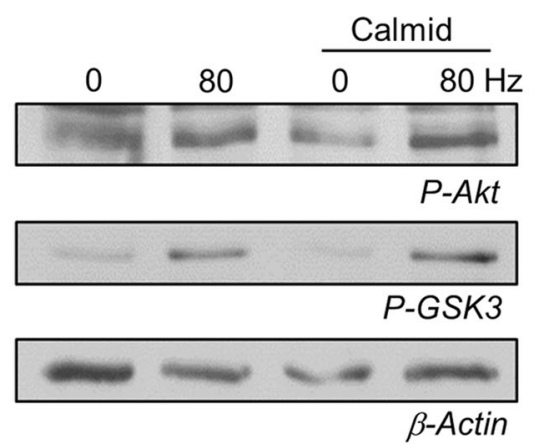

B
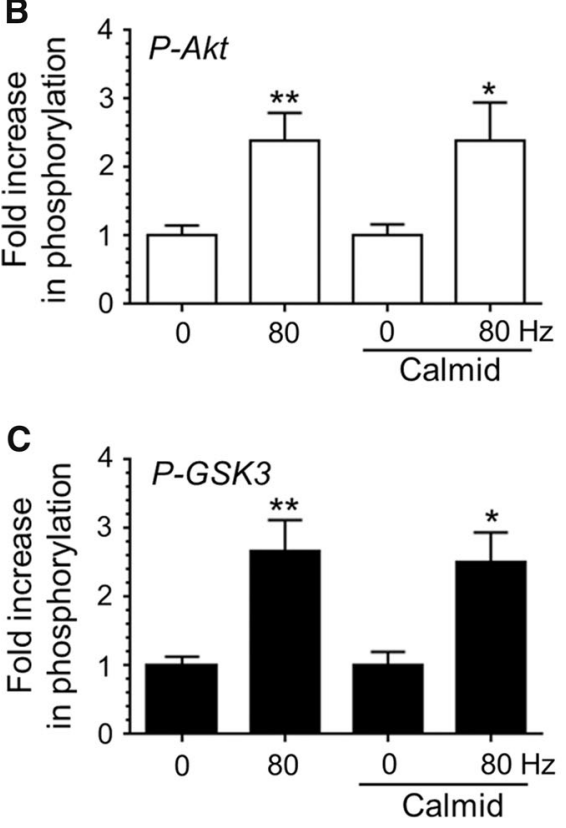

Fig. 5 Calmodulin is not the calcium sensor for activity-dependent Akt/GSK3 phosphorylation. CGNs were removed from culture medium and repolarised in incubation medium for $10 \mathrm{~min}$. Cultures were then incubated with or without incubation medium supplemented with $10 \mu \mathrm{M}$ calmidazolium for $10 \mathrm{~min}$. After this point CGNs were left to rest or challenged with either 800 action potentials $(80 \mathrm{~Hz})$ or ionomycin (IONO, $2.5 \mu \mathrm{M}$ for $1 \mathrm{~min}$ ). a, d Representative blots are displayed showing either Akt Ser473 phosphorylation $(P$ $A k t)$, GSK3 $\alpha / \beta$ Ser21/9 phosphorylation $(P-G S K 3)$ or $\beta$-Actin levels $(\beta$-Actin) after either action potential (a) or ionomycin (d) stimulation.

the transduction of activity-dependent calcium influx to the Akt signalling cascade in this work. However, PI3K-C $2 \alpha$ is insensitive to LY294002 and wortmannin at the concentrations used in this study [27], making it unlikely that PI3K-C $2 \alpha$ is involved in the activity-dependent activation of Akt. LY294002 and wortmannin sensitive Class I PI3Ks have been implicated at several stages of SV recycling in central nerve terminals, including replenishment of the readily releasable pool (RRP) from the reserve pool [28], generation of bulk endosomes [29] and SV generation from bulk endosomes [30]. PI3K is also required for the negative regulation of $\mathrm{ADBE}$ via BDNF [11]. Therefore it would be
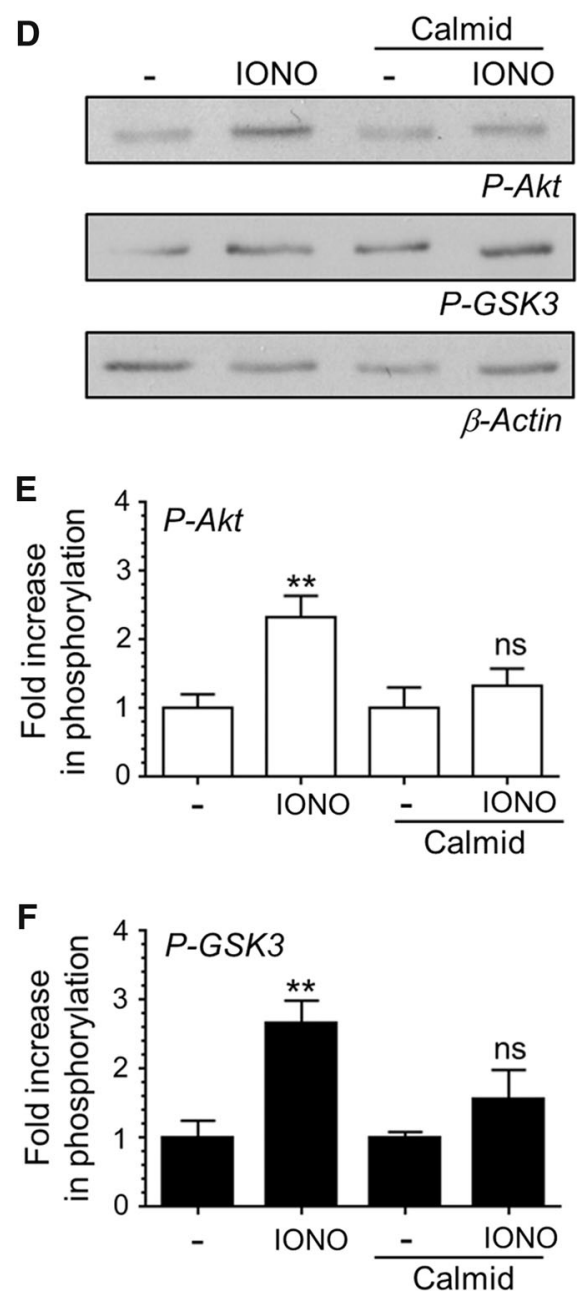

b, e The fold increase in phosphorylation of Akt Ser473 (open bars) in response to either action potentials (b) or ionomycin (e) is displayed. c, $\mathbf{f}$ The fold increase in phosphorylation of GSK $3 \alpha / \beta$ Ser21/9 (closed bars) in response to either action potentials (c) or ionomycin (f) is displayed. In all cases phosphorylation levels were corrected for protein levels using $\beta$-Actin and normalisation to the basal controls. All error bars represent $\pm \mathrm{SEM}$; $\mathrm{n}=6$ for P-Akt $80 \mathrm{~Hz}, \mathrm{n}=9$ for P-GSK3 $80 \mathrm{~Hz}, \mathrm{n}=8$ for P-Akt IONO and $\mathrm{n}=9$ for P-GSK3 IONO (students $t$ test, $n s$ non-significant, $* p<0.05$; $*^{* *} p<0.01$ basal to $80 \mathrm{~Hz}$ or basal to ionomycin per condition)

of interest to determine the activity-dependent role of PI3K in both dynamin I dephosphorylation and ADBE.

\section{Activity-Dependent Akt Phosphorylation at Nerve Terminals}

We assessed the inhibition of GSK3 and activation of Akt respectively by monitoring their phosphorylation status. Inhibition of GSK3 occurs via phosphorylation of either Ser9 of GSK3 $\alpha$ or Ser21 of GSK3 $\beta$ [9]. In this study we found that GSK3 $\alpha$ and GSK3 $\beta$ behaved in an identical manner across all stimulation conditions and 
pharmacological manipulations. We assessed activation of Akt by determining the phosphorylation status of Ser473. Phosphorylation of both Ser473 and Thr308 are required for maximal Akt activity [31, 32] and we have previously shown that the phosphorylation status of both sites respond in a similar manner to action potential stimulation in CGNs [10]. These sites are proposed to be phosphorylated by different protein kinases however. Thr308 is a PDK1 substrate, which is activated by PI3K [31, 33], whereas Ser473 can be phosphorylated by either the mTORC2 complex [32] or DNA-PK [34]. However we show that the PI3K antagonists LY294002 and wortmannin inhibit the activity-dependent phosphorylation of Ser473. This suggests that Akt phosphorylation is mediated via PI3K at central nerve terminals and studies that attempt to model this process should take this into account.

Akt and GSK3 have a wide cellular distribution, suggesting that the increased phosphorylation we observed during action potential stimulation may not be occurring at nerve terminals. We contend that these events are presynaptic, since identical stimulation protocols and modulation of both Akt and GSK3 activity-dependent phosphorylation directly impact on the phosphorylation status of dynamin I and ADBE [10, 11]. Since both dynamin I expression and $\mathrm{ADBE}$ is restricted to nerve terminals [2, 35] we argue that the activity-dependent changes in Akt and GSK3 phosphorylation are presynaptic. This statement is almost certainly not true for ionomycinevoked changes, since this ionophore will raise $\left[\mathrm{Ca}^{2+}\right]_{i}$ uniformly throughout the neuron. Ionomycin is used throughout this study as a positive control to confirm the specificity of both flunarizine and EGTA-AM in inhibiting calcium channels and global calcium increases respectively. The inhibition of ionomycin-evoked Akt and GSK3 phosphorylation by calmidazolum is intriguing however and may reflect altered activity of these enzymes by postsynaptic calcium, where Akt and GSK3 are known to have postsynaptic functions [36, 37].

A number of studies have investigated the relationship between both neuronal activity and calcium influx in the activation of Akt. Previous work in CGNs showed that chronic hyperkalemic stimulation resulted in increased Akt phosphorylation, however this was insensitive to PI3K antagonists [38]. This most likely reflects postsynaptic activation of Akt, since permanent depolarisation will reverse electrogenic glutamate transporters on the plasma membrane [39] raising extracellular glutamate concentrations and thus activating postsynaptic glutamate receptors. In agreement, shorter periods of stimulation with elevated $\mathrm{KCl}$ resulted in increased Akt phosphorylation which was reversed by PI3K antagonists [40].

\section{Transduction of Calcium Influx into Akt Phosphorylation}

We have shown that intense neuronal activity causes Akt phosphorylation via localised calcium microdomains. This suggests that a sensor must be located within the vicinity of this microdomain to couple calcium influx to PI3K/Akt activation. We have shown that calmodulin is unlikely to be the sensor since the antagonist calmidazolium was unable to inhibit action potential-evoked Akt phosphorylation. Furthermore the ability of calmidazolium to arrest ionomycin-evoked Akt phosphorylation is in agreement with the proposed location of calmodulin in the wider cytosol [15].

How could activity-dependent calcium influx be coupled to Akt phosphorylation? One potential candidate for the activity-dependent calcium sensor is the family of RasGRFs [41]. Ras-GRF activates the small G-protein Ras in a calcium-dependent manner [42] and overexpression of dominant negative Ras inhibits Akt phosphorylation evoked by $\mathrm{KCl}$ depolarisation in peripheral neurons [40]. Importantly Ras-GRF2 knockout mice display altered paired pulse facilitation, suggesting it is localised in the correct location to be activated by presynaptic calcium influx [43]. However the mechanism via which Ras-GRF is activated by calcium influx is thought to be via calciumbound calmodulin binding to its IQ domain [42, 44]. Since calmodulin inhibition had no effect on activity-dependent Akt phosphorylation, it may be that Ras-GRF is not the sensor for this event.

A second possibility is that there may not be calcium a sensor at all. In this model the requirement for localised calcium increases is an indirect result of the presynaptic release of growth factors such as BDNF. This event only occurs in neurons during intense neuronal activity, very similar to that observed in this study [45]. This is potentially important for Akt phosphorylation, since PI3K can activate either PDK1 or the mTORC2 complex via growth factor receptors [46]. In support, we have shown that exogenous addition of BDNF triggers phosphorylation of Ser473 in CGNs via a potential PI3K-dependent route [11]. Thus our manipulations to either block calcium entry or buffer the calcium microdomain should also arrest BDNF release during intense activity, stopping it feeding back to increase Akt phosphorylation via PI3K. This hypothesis is testable using agents that sequester extracellular BDNF and we are currently investigating the effect of these agents on activity-dependent Akt phosphorylation [47].

In summary, we have shown that during intense neuronal activity phosphorylation of Akt (and subsequent inhibition of GSK3) is dependent on localised calcium 
microdomains formed by voltage-gated calcium channels. The identity of the sensor or release mechanism which transduce increased $\left[\mathrm{Ca}^{2+}\right]_{\mathrm{i}}$ remains unidentified. This is an important question to address, since we predict that modulation of these events should impact on the extent of ADBE in central nerve terminals.

Acknowledgments This work was supported by the Medical Research Council (Grant Number: G1002117) and a Ph.D. studentship from the Biotechnology and Biological Sciences Research Council.

Open Access This article is distributed under the terms of the Creative Commons Attribution 4.0 International License (http://crea tivecommons.org/licenses/by/4.0/), which permits unrestricted use, distribution, and reproduction in any medium, provided you give appropriate credit to the original author(s) and the source, provide a link to the Creative Commons license, and indicate if changes were made.

\section{References}

1. Kononenko NL, Haucke V (2015) Molecular mechanisms of presynaptic membrane retrieval and synaptic vesicle reformation. Neuron 85(3):484-496. doi:10.1016/j.neuron.2014.12.016

2. Clayton EL, Cousin MA (2009) The molecular physiology of activity-dependent bulk endocytosis of synaptic vesicles. J Neurochem 111(4):901-914. doi:10.1111/j.1471-4159.2009.06384.x

3. Granseth B, Odermatt B, Royle SJ, Lagnado L (2006) Clathrin-mediated endocytosis is the dominant mechanism of vesicle retrieval at hippocampal synapses. Neuron 51(6):773-786. doi:10.1016/j.neuron. 2006.08.029

4. Watanabe S, Rost BR, Camacho-Perez M, Davis MW, SohlKielczynski B, Rosenmund C, Jorgensen EM (2013) Ultrafast endocytosis at mouse hippocampal synapses. Nature 504(7479):242-247. doi:10.1038/nature12809

5. Watanabe S, Trimbuch T, Camacho-Perez M, Rost BR, Brokowski B, Sohl-Kielczynski B, Felies A, Davis MW, Rosenmund C, Jorgensen EM (2014) Clathrin regenerates synaptic vesicles from endosomes. Nature. doi:10.1038/nature13846

6. Kokotos AC, Cousin MA (2014) Synaptic vesicle generation from central nerve terminal endosomes. Traffic. doi:10.1111/tra. 12235

7. Clayton EL, Anggono V, Smillie KJ, Chau N, Robinson PJ, Cousin MA (2009) The phospho-dependent dynamin-syndapin interaction triggers activity-dependent bulk endocytosis of synaptic vesicles. J Neurosci 29(24):7706-7717. doi:10.1523/jneurosci.1976-09.2009

8. Clayton EL, Sue N, Smillie KJ, O'Leary T, Bache N, Cheung G, Cole AR, Wyllie DJ, Sutherland C, Robinson PJ, Cousin MA (2010) Dynamin I phosphorylation by GSK3 controls activitydependent bulk endocytosis of synaptic vesicles. Nat Neurosci 13(7):845-851. doi:10.1038/nn.2571

9. Frame S, Cohen P (2001) GSK3 takes centre stage more than 20 years after its discovery. Biochem J 359(Pt 1):1-16

10. Smillie KJ, Cousin MA (2012) Akt/PKB controls the activitydependent bulk endocytosis of synaptic vesicles. Traffic 13(7):1004-1011. doi:10.1111/j.1600-0854.2012.01365.x

11. Smillie KJ, Pawson J, Perkins EM, Jackson M, Cousin MA (2013) Control of synaptic vesicle endocytosis by an extracellular signalling molecule. Nat Commun 4:2394. doi:10.1038/ncomms3394

12. Tan TC, Valova VA, Malladi CS, Graham ME, Berven LA, Jupp OJ, Hansra G, McClure SJ, Sarcevic B, Boadle RA, Larsen MR, Cousin
MA, Robinson PJ (2003) Cdk5 is essential for synaptic vesicle endocytosis. Nat Cell Biol 5(8):701-710. doi:10.1038/ncb1020

13. Cousin MA, Nicholls DG, Pocock JM (1993) Flunarizine inhibits both calcium-dependent and -independent release of glutamate from synaptosomes and cultured neurones. Brain Res 606(2):227-236

14. Adler EM, Augustine GJ, Duffy SN, Charlton MP (1991) Alien intracellular calcium chelators attenuate neurotransmitter release at the squid giant synapse. J Neurosci 11(6):1496-1507

15. Chin D, Means AR (2000) Calmodulin: a prototypical calcium sensor. Trends Cell Biol 10(8):322-328

16. Joyal JL, Burks DJ, Pons S, Matter WF, Vlahos CJ, White MF, Sacks DB (1997) Calmodulin activates phosphatidylinositol 3-kinase. J Biol Chem 272(45):28183-28186

17. Wu XS, McNeil BD, Xu J, Fan J, Xue L, Melicoff E, Adachi R, Bai L, Wu LG (2009) $\mathrm{Ca}(2+)$ and calmodulin initiate all forms of endocytosis during depolarization at a nerve terminal. Nat Neurosci 12(8):1003-1010. doi:10.1038/nn.2355

18. Balla T (2013) Phosphoinositides: tiny lipids with giant impact on cell regulation. Physiol Rev 93(3):1019-1137. doi:10.1152/phys rev.00028.2012

19. Chasserot-Golaz S, Coorssen JR, Meunier FA, Vitale N (2010) Lipid dynamics in exocytosis. Cell Mol Neurobiol 30(8):1335-1342. doi:10.1007/s10571-010-9577-x

20. Osborne SL, Wen PJ, Meunier FA (2006) Phosphoinositide regulation of neuroexocytosis: adding to the complexity. J Neurochem 98(2):336-342. doi:10.1111/j.1471-4159.2006.03892.x

21. Mazza S, Maffucci T (2011) Class II phosphoinositide 3-kinase C2alpha: what we learned so far. Int $\mathrm{J}$ Biochem Mol Biol 2(2):168-182

22. Leibiger B, Moede T, Uhles S, Barker CJ, Creveaux M, Domin J, Berggren PO, Leibiger IB (2010) Insulin-feedback via PI3KC2alpha activated PKBalpha/Akt1 is required for glucose-stimulated insulin secretion. FASEB J 24(6):1824-1837. doi:10.1096/ fj.09-148072

23. Meunier FA, Osborne SL, Hammond GR, Cooke FT, Parker PJ, Domin J, Schiavo G (2005) Phosphatidylinositol 3-kinase C2alpha is essential for ATP-dependent priming of neurosecretory granule exocytosis. Mol Biol Cell 16(10):4841-4851. doi:10. 1091/mbc.E05-02-0171

24. Dominguez V, Raimondi C, Somanath S, Bugliani M, Loder MK, Edling CE, Divecha N, da Silva-Xavier G, Marselli L, Persaud SJ, Turner MD, Rutter GA, Marchetti P, Falasca M, Maffucci T (2011) Class II phosphoinositide 3-kinase regulates exocytosis of insulin granules in pancreatic beta cells. J Biol Chem 286(6):4216-4225. doi:10.1074/jbc.M110.200295

25. Wen PJ, Osborne SL, Morrow IC, Parton RG, Domin J, Meunier FA (2008) $\mathrm{Ca}^{2+}$-regulated pool of phosphatidylinositol-3-phosphate produced by phosphatidylinositol 3-kinase C2alpha on neurosecretory vesicles. Mol Biol Cell 19(12):5593-5603. doi:10. 1091/mbc.E08-06-0595

26. Gaidarov I, Smith ME, Domin J, Keen JH (2001) The class II phosphoinositide 3-kinase C2alpha is activated by clathrin and regulates clathrin-mediated membrane trafficking. Mol Cell 7(2):443-449

27. Domin J, Pages F, Volinia S, Rittenhouse SE, Zvelebil MJ, Stein RC, Waterfield MD (1997) Cloning of a human phosphoinositide 3-kinase with a $\mathrm{C} 2$ domain that displays reduced sensitivity to the inhibitor wortmannin. Biochem J 326(Pt 1):139-147

28. Cousin MA, Malladi CS, Tan TC, Raymond CR, Smillie KJ, Robinson PJ (2003) Synapsin I-associated phosphatidylinositol 3-kinase mediates synaptic vesicle delivery to the readily releasable pool. J Biol Chem 278(31):29065-29071. doi:10.1074/jbc. M302386200

29. Holt M, Cooke A, Wu MM, Lagnado L (2003) Bulk membrane retrieval in the synaptic terminal of retinal bipolar cells. J Neurosci 23(4):1329-1339 
30. Richards DA, Rizzoli SO, Betz WJ (2004) Effects of wortmannin and latrunculin $\mathrm{A}$ on slow endocytosis at the frog neuromuscular junction. J Physiol 557(Pt 1):77-91. doi:10.1113/jphysiol.2004. 062158

31. Alessi DR, James SR, Downes CP, Holmes AB, Gaffney PR, Reese CB, Cohen P (1997) Characterization of a 3-phosphoinositide-dependent protein kinase which phosphorylates and activates protein kinase Balpha. Curr Biol 7(4):261-269

32. Sarbassov DD, Guertin DA, Ali SM, Sabatini DM (2005) Phosphorylation and regulation of $\mathrm{Akt} / \mathrm{PKB}$ by the rictor-mTOR complex. Science 307(5712):1098-1101. doi:10.1126/science. 1106148

33. Brazil DP, Hemmings BA (2001) Ten years of protein kinase B signalling: a hard Akt to follow. Trends Biochem Sci 26(11):657-664

34. Bozulic L, Hemmings BA (2009) PIKKing on PKB: regulation of PKB activity by phosphorylation. Curr Opin Cell Biol 21(2):256-261. doi:10.1016/j.ceb.2009.02.002

35. Ferguson SM, De Camilli P (2012) Dynamin, a membrane-remodelling GTPase. Nat Rev Mol Cell Biol 13(2):75-88. doi:10. 1038/nrm3266

36. Li Z, Jo J, Jia JM, Lo SC, Whitcomb DJ, Jiao S, Cho K, Sheng M (2010) Caspase-3 activation via mitochondria is required for long-term depression and AMPA receptor internalization. Cell 141(5):859-871. doi:10.1016/j.cell.2010.03.053

37. Peineau S, Taghibiglou C, Bradley C, Wong TP, Liu L, Lu J, Lo E, Wu D, Saule E, Bouschet T, Matthews P, Isaac JT, Bortolotto ZA, Wang YT, Collingridge GL (2007) LTP inhibits LTD in the hippocampus via regulation of GSK3beta. Neuron 53(5):703-717. doi:10.1016/j.neuron.2007.01.029

38. Lafon-Cazal M, Perez V, Bockaert J, Marin P (2002) Akt mediates the anti-apoptotic effect of NMDA but not that induced by potassium depolarization in cultured cerebellar granule cells. Eur J Neurosci 16(4):575-583
39. Nicholls DG (1993) The glutamatergic nerve terminal. Eur J Biochem/FEBS 212(3):613-631

40. Vaillant AR, Mazzoni I, Tudan C, Boudreau M, Kaplan DR, Miller FD (1999) Depolarization and neurotrophins converge on the phosphatidylinositol 3-kinase-Akt pathway to synergistically regulate neuronal survival. J Cell Biol 146(5):955-966

41. Fernandez-Medarde A, Santos E (2011) The RasGrf family of mammalian guanine nucleotide exchange factors. Biochim Biophys Acta 1815(2):170-188. doi:10.1016/j.bbcan.2010.11.001

42. Farnsworth CL, Freshney NW, Rosen LB, Ghosh A, Greenberg ME, Feig LA (1995) Calcium activation of Ras mediated by neuronal exchange factor Ras-GRF. Nature 376(6540):524-527. doi: $10.1038 / 376524 \mathrm{a} 0$

43. Li S, Tian X, Hartley DM, Feig LA (2006) Distinct roles for Rasguanine nucleotide-releasing factor 1 (Ras-GRF1) and Ras-GRF2 in the induction of long-term potentiation and long-term depression. J Neurosci 26(6):1721-1729. doi:10.1523/JNEUROSCI.3990-05. 2006

44. Bahler M, Rhoads A (2002) Calmodulin signaling via the IQ motif. FEBS Lett 513(1):107-113

45. Matsuda N, Lu H, Fukata Y, Noritake J, Gao H, Mukherjee S, Nemoto T, Fukata M, Poo MM (2009) Differential activity-dependent secretion of brain-derived neurotrophic factor from axon and dendrite. J Neurosci 29(45):14185-14198. doi:10.1523/ JNEUROSCI.1863-09.2009

46. Oh WJ, Jacinto E (2011) mTOR complex 2 signaling and functions. Cell Cycle 10(14):2305-2316

47. Chen DY, Bambah-Mukku D, Pollonini G, Alberini CM (2012) Glucocorticoid receptors recruit the CaMKIIalpha-BDNF-CREB pathways to mediate memory consolidation. Nat Neurosci 15(12):1707-1714. doi:10.1038/nn.3266 